http://dx.doi.org/10.4314/jae.v17i1.15

\title{
Capacity Building Needs of Farmers for Safe Agro-chemical Use/Application in Niger State, Nigeria
}

\author{
Umar, S. I., Olaleye, R. S., Ndanitsa, M. A., Ibrahim, M., Tsado, J.H. and Sadiq, \\ M.S. \\ Dept. of Agricultural Economics and Extension Technology, F. U.T., Minna \\ umarsheshi@gmail.com \\ 08039192721
}

\begin{abstract}
In order to determine the capacity building needs of farmers for safe agro-chemical use in Niger State, the study examined awareness of safety measures for agrochemical usage, sources of awareness, practice of safety measures and training needs of farmers. One hundred and twenty farmers were randomly selected from three local government areas in the state. Validated interview schedule with reliability coefficient of 0.89 was used to collect data. Data collected were analyzed using descriptive statistics and correlation analysis. All the respondents were aware of wearing of protective clothing and avoiding drinking/eating during spraying, safety measure such as avoiding off label use (7.50\%) had low awareness level. The major sources of awareness were friend/relatives (55.00\%). The most widely practised safety measure was avoiding ingesting or inhaling chemicals (91.67\%), while the least practised safety measure was avoiding off label use (2.50\%). Reasons given for not practicing some safety measures include heaviness of protective clothing (17.50\%) and unreadable nature of instruction labels (14.17\%). Major areas of training needs of the respondents were application (61.67\%) and handling (52.50\%) of agro-chemicals. A positive significant correlation existed between education $(r=$ $0.461)$, farming experience $(r=0.337)$, farm income $(r=0.307)$ and practice of safety measures. It was therefore recommended that enlightenment campaign should be carried out in the State to raise awareness level for safe use of agro-chemicals in the agricultural transformation programme, while the characters of the instruction labels should be boldly written to facilitate reading and practice of safety measures.
\end{abstract}

\section{Introduction}

Agriculture is classified as one of the most hazardous sectors both in industrialized and developing countries with an estimated number of 170,000 agricultural workers being killed yearly (International Labor Organization ILO, 2004). This implies that agricultural workers are twice at risk of dying on the job when compared with workers in other sectors. For quit sometimes now there has been public concern about the crop protection and pest control chemicals, deliberately developed to be toxic to some living organisms which is the reason for their commercials utilization (Sajo and Mustapha,2007). Accidental ingestion of agro-chemicals by humans and animals might produce adverse effect because they are very poisonous. Thus, there are a lot of health risks to the farmers and others handling and spraying agro-chemicals.

The negative human health and environment consequences arising from misuses of agro-chemicals is of great concern as farmers, farm workers and rural population experience both acute and chronic health effects from agro-chemical exposure. The 


\section{Journal of Agricultural Extension}

Vol. 17 (1) June, 2013

ISSN 1119-944X

World Health Organization (WHO) estimates that globally, exposure to pesticide caused an annual 20,000 death and at least 3 million cases of poisoning are recorded annually with over $70 \%$ occurring in Africa (WHO, 2001). Other estimates suggest that annual figure for pesticide poisoning is as high as 20 million in developing countries alone (Jenyaratnam, 1990). Ajayi (2006) disputed these figures suggesting that those cases should be as much as even treble, since many cases are not reported in rural areas of developing countries. According to Sajo and Mustapha (2007) most human health and environment hazards are caused by mishandling of agrochemicals from their purchases, storage, application and disposal of pesticide waste and containers. The author further stressed that hazards can be minimized if stakeholders abide by the guideline on safe use of agrochemicals.

World Health Organization (2001) in agricultural census reported that most of the agro-chemical operators are hired farm workers that lack agricultural background and use employment in the agricultural sector as an entry level job. The report also reveals that language barrier also exists which can impede following safety information on labels. All of those may increase health safety hazard in the agricultural work place (ILO, 2004). Training workshop on safe use of agrochemicals organized by Daimina Project (2004) recommended precautionary measures by farmers when applying the various agrochemicals such as wearing of nose shield to avoid inhalation, protective clothing, rubber gloves and boots, restraining from smoking, eating and drinking during chemical applications, covering of food and water to avoid contamination among others. This study is significant in that the identification of capacity building needs of farmers for safe agro-chemical use and application will inform decision makers and instruct policy to reduce the negative effect of agro-chemicals in the agricultural transformation programme.

\section{Objectives of the study}

The broad objective of the study is to examine the capacity building needs of farmers for safe agro-chemical use in Niger State: the specific objectives are to:

1. determine the awareness of safety measures of agrochemicals use;

2. determine sources of awareness of safety measures;

3. determine the extent of practice of safety measures; and

4. identify areas of training needs of the respondents.

\section{Hypothesis of the study}

There is no correlation between the socio-economic characteristics of the respondents and practice of safety measures of agro-chemicals.

\section{Methodology}

Niger State falls within latitudes $8^{0}-10^{0} \mathrm{~N}$ and longitudes $3^{0}-8^{0}$ East. The State is located in the Southern Guinea Savanna ecological zone of Nigeria. The climate of the state is characterized by distinct wet and dry seasons. Some of the rains fed crops produced are maize, millet, sorghum, yam, groundnut, rice, cowpea, cassava and melon. Economic trees grown include; mango, oil palm shea butter trees, locust beans, orange and guava. Vegetable crops such as pepper tomatoes spinach and 
okra are grown during the dry season along the banks of state's major rivers through irrigation. Animals reared include cattle, goat, sheep, camel, donkey and poultry (Niger State Agricultural Development Project, 2002).

Three local government areas (Mokwa, Paikoro and Wushishi LGAs) one from each of the 3 agricultural zones in the state were randomly selected for the study. A total of 12 villages were randomly selected from the LGAs. Based on the population of farmers in each of the selected village, a total of 120 respondents were sampled for the study from established sampling frame of 1,200 farmers. A validated interview schedule which was subjected to Cronbach's Alpha reliability test $(r=0.89)$ was used for data collection. Data were collected on the farmer's socio-economic characteristics and awareness of safety measures as well as on the practices of the safety measures and training needs. Age, educational level and farming experience were measured in years; while income, farm size and marital status were measured in naira, hectare and dummy respectively. Awareness, sources of awareness and areas of training needs were measured by asking the respondents to indicate the awareness of any safety measure, their sources of awareness and areas of training needs. Extent of practice of safety measures was measured by asking the respondents to indicate the number of safety measures they practised regularly. The maximum score for extent of practice of safety measures was 16 while the minimum score was 1. Field survey for data collection was conducted between January and March, 2012. Data were analyzed using descriptive statistics (frequency and percentage) and correlation analysis.

\section{Results and Discussion Socio-economic characteristics of respondents}

Result in Table 1 indicates that $12.50 \%$ of the respondents were less than 20 years, while $31.70 \%$ and $30.00 \%$ of the respondents were in the ranges of $20-29$ years and 30-39 years, respectively. These findings suggest that majority of the respondents were in their active age ranges of 20-39years and Hamidu et al. (2006) reported that young active farmers are more willing to adopt and practice new agricultural technologies than the older farmers. Table 1 further reveals that majority $(94.20 \%)$ of the respondents were married. Findings on educational status of the respondents shows that $(54.20 \%$ did not acquire formal education, while only $(9.20 \%)$ have tertiary education. This result reveals that more than half of the respondents did not acquire formal education.

Majority $(62.50 \%)$ of the respondents had more than 15 years of farming experience, which implies that the majority of the respondents have long years of experience. Most of the respondents (68.30\%) realized income of between $\$ 151$, 000 - $\$ 250,000$. Only $27.50 \%$ of the respondents realized above $A 250,000$ as farm income. Similarly, Table 1 shows that $(35.00 \%)$ of the respondents cultivated less than 1 hectare, while $(45.80 \%)$ cultivated between 1-2 hectares. The mean farm size of the respondents was 1.3 hectare. 
Table 1

Socio-economic characteristics of the respondents.

\begin{tabular}{|c|c|c|}
\hline Variables & Frequency & Percentage \\
\hline \multicolumn{3}{|l|}{ Age } \\
\hline >20years & 15 & 12.50 \\
\hline 20-29years & 38 & 31.70 \\
\hline $30-39$ years & 36 & 30.00 \\
\hline 40-49years & 15 & 12.50 \\
\hline $50-59$ & 10 & 8.30 \\
\hline 60 and above & 6 & 5.00 \\
\hline Total & 120 & 100.00 \\
\hline \multicolumn{3}{|l|}{ Marital status } \\
\hline Single & 7 & 5.80 \\
\hline Married & 113 & 94.20 \\
\hline Total & 120 & 100.00 \\
\hline \multicolumn{3}{|l|}{ Education } \\
\hline No formal education & 65 & 54.20 \\
\hline Primary education & 24 & 20.00 \\
\hline Secondary education & 20 & 16.60 \\
\hline Tertiary education & 11 & 9.2 \\
\hline Total & 120 & 100.00 \\
\hline \multicolumn{3}{|l|}{ Farming experience } \\
\hline$>5$ years & 6 & 5.00 \\
\hline 6-10years & 19 & 15.80 \\
\hline 11-15years & 20 & 16.70 \\
\hline Above 15years & 75 & 62.50 \\
\hline Total & 120 & 100.00 \\
\hline \multicolumn{3}{|l|}{ Farm Income } \\
\hline A50,000- $\$ 100,000$ & 2 & 1.70 \\
\hline$\# 101,000-\$ 150,000$ & 3 & 2.50 \\
\hline A151,000- $\ 200,000$ & 45 & 37.50 \\
\hline A201,000- A250,000 & 37 & 30.80 \\
\hline 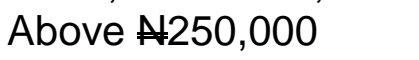 & 33 & 27.50 \\
\hline Total & 120 & 100.00 \\
\hline \multicolumn{3}{|l|}{ Farm size } \\
\hline$>1$ ha. & 42 & 35.00 \\
\hline 1.1ha.2ha & 55 & 45.80 \\
\hline 2.1ha-3ha & 23 & 19.20 \\
\hline Total & 120 & 100.00 \\
\hline
\end{tabular}

Source: Field survey, 2012

\section{Awareness of safety measures}

Data in Table 2 show that hundred percent each of the respondents were aware of wearing protective clothing, wearing of rubber gloves/boots and avoiding drinking, eating or smoking during spraying, respectively. Similarly, $92.50 \%$ of the respondent were aware of wearing of nose shield to prevent inhalation, while $91.67 \%$ of the respondents knew about avoiding ingesting or inhaling of chemicals. Others included no spraying of chemical during windy periods (81.67\%), covering of food and water 


\section{Journal of Agricultural Extension}

Vol. 17 (1) June, 2013

ISSN 1119-944X

during spraying to avoid contamination (73.33\%), avoiding skin contact with chemical $(61.66 \%)$, no pouring of unused chemicals into drinking, irrigation or running water $(54.17 \%)$, reading of instruction on label before using $(45.83 \%)$, puncturing and burying of used agro-chemical containers in the soil $(35.00 \%)$, bathing with soap and water after spraying chemical (30.00\%), keeping of chemical under lock and key away from children (21.67\%), washing of spraying cloth separately from other cloths $(15.83 \%)$, buying of chemical from a reputable sources $(13.33 \%)$ and avoiding off label use $(7.50 \%)$. The findings reveal that there is low level of awareness on the last four safety measures listed above in the state. Thus, the extension agents should take special cognizance of those safety measures for appropriate information dissemination to farmers.

Table 2

Awareness of safety measure by the respondents

\begin{tabular}{lll}
\hline Awareness of safety measure & Frequency & Percentage \\
\hline Buying of chemical from reputable sources & 16 & 13.33 \\
Reading of instruction on label before using & 55 & 45.83 \\
Do not spray during windy period & 98 & 81.67 \\
Wearing of protective clothing, & 120 & 100.00 \\
Wearing of nose shield to avoid inhalation & 111 & 92.50 \\
Wearing of rubber gloves and boots & 120 & 100.00 \\
Do not drink, eat or smoke while spraying & 120 & 100.00 \\
Avoid skin contact with chemicals & 74 & 61.66 \\
Do not ingest or inhale chemicals & 110 & 91.67 \\
Covering of food and water during spraying to avoid & 88 & 73.33 \\
contamination & & \\
Do not pour unused chemical in to drinking, irrigation or & 65 & 54.17 \\
runinig water & & \\
Puncture used chemical containers and bury in the soil & 42 & 35.00 \\
Avoid off- label use & 9 & 7.50 \\
Both with soap and water after spraying chemicals & 36 & 30.00 \\
Wash spraying cloths separately from other cloths & 19 & 15.83 \\
Keep chemicals under lock and key away from children & 26 & 21.67 \\
\hline
\end{tabular}

Source: Field survey, 2012

* Multiple responses

\section{Sources of awareness}

Majority (55.00\%) of the respondents got information on safety measures from friends and relatives through conversation. This was followed by cooperative societies (35.00\%) and radio jingles $(25.00 \%)$, while extension agents $(20.83 \%)$ ranked fourth as a source of information on safety measures. The implication of the findings is that the majority of respondents had more interaction with non professionals (friends and relatives) than the extension agents who are supposed to be a reliable and better source of awareness on safety measures. 
Table 3

ISSN 1119-944X

Distribution of respondents according to their sources of awareness of safety measures.

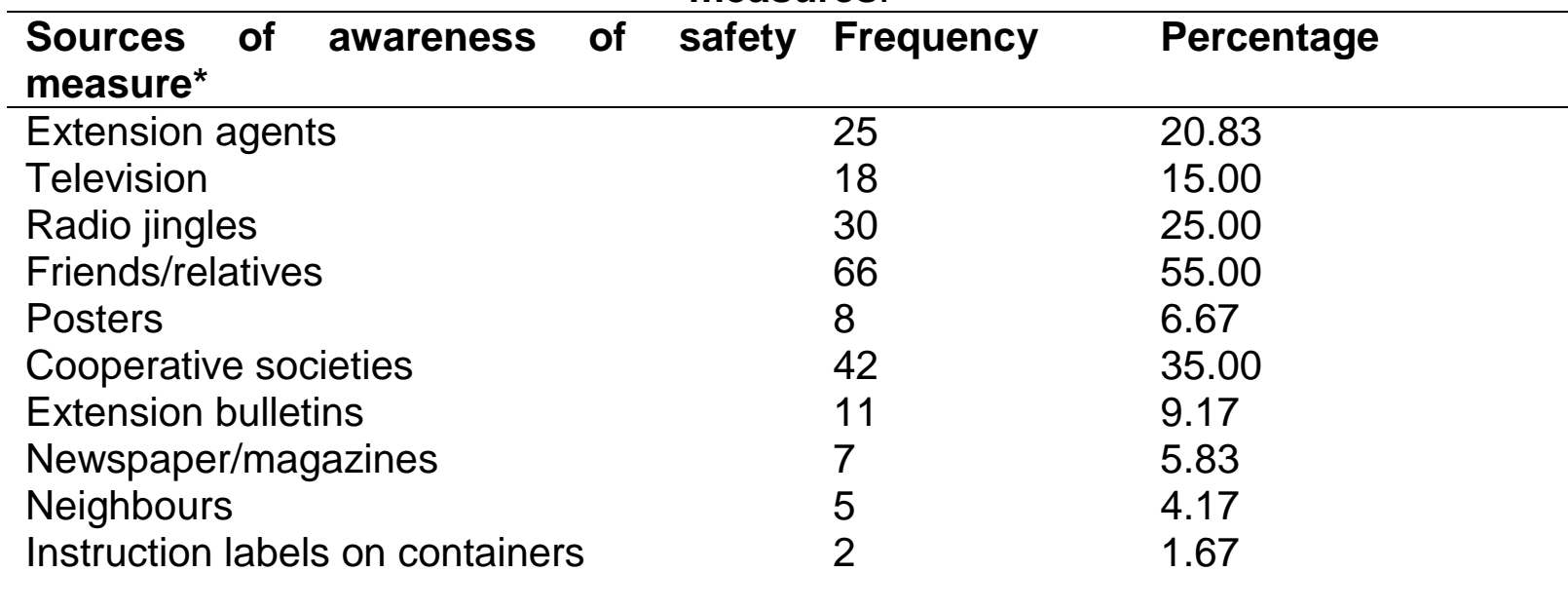

Source: Field survey, 2012

${ }^{*}$ Multiple responses

\section{Practice of safety measures}

Table 4 shows practice of safety measures by the respondents. Only one quarter of the respondents $(25.83 \%)$ read instructions on the label before using the chemicals. Also, only $23.33 \%$ avoided pouring of unused chemicals into drinking, irrigation or running water. It is pertinent to note that the practice of wearing rubber gloves/boot, protective cloth and nose shield had low responses with $22.50 \%, 18.33 \%$ and $15.83 \%$ response rate, respectively. Other safety measures that were not well practised included keeping of chemicals under lock and key away from the children $(10.83 \%)$, puncturing and burying of used agro-chemical containers in the soil $(7.50 \%)$, washing of spraying cloth separately from other cloths $(6.67 \%)$ and avoiding off label use $(2.50 \%)$. This could be attributed to the low level of awareness and knowledge of the respondents on the devastating effect of the agro-chemicals. This poses a possible threat to farming families, animals, food and agriculture in the state. 
Table 4

ISSN 1119-944X

Practice of safety measures by the respondents.

\begin{tabular}{lll}
\hline Practice of safety measure* & Frequency & Percentage \\
\hline Buying of chemical from reputable source & 6 & 5.00 \\
Reading of instruction on label before using & 31 & 25.83 \\
Avoiding spray during windy period & 94 & 78.33 \\
Wearing of protective clothing & 22 & 18.33 \\
Wearing of nose shield to avoid inhalation & 19 & 15.83 \\
Wearing of rubber gloves and boots & 27 & 22.50 \\
Avoiding drinking,eating or smoking while spraying & 103 & 85.83 \\
Avoid skin contact with chemicals & 65 & 54.17 \\
Avoiding ingestion or inhaling chemicals & 110 & 91.67 \\
Covering of food and water during spraying to avoid & 76 & 63.33 \\
contamination & & \\
Avoiding pouring unused chemical in to drinking, irrigation or or & 28 & 23.33 \\
running water & & \\
Puncture used agro-chemical containers and bury in the siol & 9 & 7.50 \\
Avoiding off- label use & 3 & 2.50 \\
Bathing with soap and water after spraying & 34 & 28.33 \\
Washing of spraying cloth separately from other cloths & 8 & 6.67 \\
Keep chemicals under lock and key away from children & 13 & 10.83 \\
\hline Source: Field survey, 2012 & & \\
${ }^{*}$ Multiple responses & &
\end{tabular}

\section{Reasons for not practising safety measures}

When asked to give reasons for not practicing some safety measures, $8.33 \%$ of the respondents in Table 5 indicated that they did not know the reputable dealers of the agro-chemicals in their area, while $17.50 \%$ of respondents indicated that they are not practicing wearing of protective cloth and rubber glove/ boots because they are too heavy to wear. On the other hand, some of the respondents $(14.17 \%)$ reported that they are not practicing reading of instructions before using agro-chemicals because character of some instruction labels are too small or tiny to read. Other respondents constituting $15.00 \%$ indicated that they did not take some safety measure such as avoiding skin contact with chemicals, washing spraying cloth separately from other cloths and keeping chemicals under lock and key away from children very serious. This point to the problem of information provided by non-professionals (friends and relatives).This implies that a considerable awareness campaign is needed to promote the practice of some safety measures. 
Table 5

Reasons for not practicing safety measures

\begin{tabular}{|c|c|c|}
\hline Reasons for not practice safety measures* & Frequency & Percentage \\
\hline Did not know the reputable dealers & 10 & 8.33 \\
\hline $\begin{array}{l}\text { Protective cloths and rubber gloves/boots are } \\
\text { heavy to wear }\end{array}$ & 21 & 17.50 \\
\hline Character of instruction labels too small to read & 17 & 14.17 \\
\hline Did not take safety measures very serious & 18 & 15.00 \\
\hline
\end{tabular}

Source: Field survey 2012

${ }^{*}$ Multiple responses

\section{Training needs of farmers}

Table 6 reveals that $61.7 \%$ of the respondents were in need of training on application of agro-chemicals on how to use knapsack sprayer, type of agro-chemical to apply under different environment, how to apply it and when it should be applied. Similarly, $52.5 \%$ of the respondents were in need of training on handling of agro-chemicals such as mixing and cleaning of agro-chemical. Other areas of training needs were disposal of waste/containers $(49.2 \%)$, storage (38.3\%) and transportation $(10.0 \%)$ of agro-chemicals. This result highlights the areas of capacity building needs of farmers; which suggest that most of the respondents were in need of training on application, handling and disposal of waste/container of agro-chemicals. Attending to those areas of needs will go a long way in building farmers' capacity for safe use and application of agro-chemicals, thereby minimizing pest resistance, damage to pollinating insects, phytotoxicity, agro-chemical drift, air pollution as well as hazards to human and wildlife species.

Table 6

Training needs of the respondents

Training needs*

Percentage

\begin{tabular}{lcc} 
Transportation of agro-chemicals & 12 & 10.00 \\
Storage of agro-chemicals & 46 & 38.33 \\
Handling of agro-chemicals & 63 & 52.50 \\
Application of agro-chemicals & 74 & 61.67 \\
Disposal of waste/containers of agro-chemicals & 59 & 49.17 \\
\hline
\end{tabular}

Source: Field survey, 2012

* Multiple responses

\section{Correlation between socio-economic characteristics and practice of safety measures.}

Data in Table 7 shows a negative correlation between age and practice of safety measures. This implies that as farmers get older, they become more conservative and tend to abandon safety measures. In a related study, Hamidu et al. (2006) reported that old farmers often tend to be more conservative in relation to adoption of innovation and practices. However, educational level, farming experience and farm income of the respondents had positive correlation with the practice of safety 
measures, indicating that a unit increase in those variables will ensure constant practice of the safety measures by the respondents.

Table 7

Correlation between socio-economic characteristics of the respondents and practice of safety measures

\begin{tabular}{ll}
\hline Description of variables & Practice of safety measures \\
\hline Age (years) & $-0.290^{*}$ \\
Marital status (dummy) & $0.183^{\mathrm{NS}}$ \\
Education ( years) & $0.461^{*}$ \\
Farming experience (years) & $0.337^{\star}$ \\
Farm income (naira) & $0.307^{\star}$ \\
Farm size (hectare) & $0.190^{\mathrm{NS}}$ \\
Practice of safety measures (number) & 1.00 \\
\hline
\end{tabular}

Source: Computed from field survey, 2012

${ }^{*}$ correlation is significant at 0.05 levels

r-values at $0.05=0.232$

$\mathrm{NS}=$ Not significant

\section{Conclusion}

Most of the respondents were in need of training on application and handling of agrochemicals. Education, farming experience and farm income had positive correlation with practice of safety measures by the respondents.

\section{Recommendations}

Extension awareness campaign should be carried out in the state to raise the level of awareness on the safety measures of agro-chemicals and for farmers to take the safety measures very serious.

List of reputable agro-chemical dealers in the state should be compiled by extension agent and made known to the farmers for patronage.

Lighter protective clothing and rubber boots should be designed by their manufacturers for farmers' conveniences, while the character of the instruction labels on the containers of agro-chemicals should be boldly written for ease of reading.

To build farmers' capacity for safe use and application of agro-chemicals in the state, extension education should pay particular attention to training the farmers on agrochemical safety issues such as application, handling and disposal of waste/containers of agro-chemicals. This is necessary to prevent both human and animal health hazards as well as environmental hazards. 


\section{References}

Ajayi A.O. (2006) A study on occupational safety practices among rural farmers in Ile-Ife area of Osun State, Nigeria: An emphasis on relevant training needs; Department of Agricultural Research. Journal of agricultural and biological science 2(5), pp. 227-235.

Daimina Project (2004) Safe use and handling of crop protection products. Training work jointly organized by USAID, IFDC, IITA, CANDEL, Union Bank, WARDA, NCRI, SG 2000, RIFAN and FCT- ADP, held at Gwagwalada and Pandagi FCT.

Hamidu B.M., Murtala, N., Illiyasu, A.Y. and Adamu I.P. (2006) Assessment of the adoption of afforestation innovation in Dambatta Local Government Area, of Kano State. Journal of Agricultural Extension Vol. 9, pp.51-62.

International Labaur Organization (2004). Safety and health in the use of agrochemicals. pp.69

Jeyaratnam, J. (1990) Acute pesticide: A major problems world health statistics quarterly (43), pp. 139-144.

Niger State Agricultural Development Project (2002) Impact Study Final Report, pp.1-128.

Sajo, .A.A. and Mustapha A.B (2007). Safety factors in effective weed management for sustainable environment .A symposium paper presented at the weed $35^{\text {th }}$ Annual Conferences of the Weed Science Society of Nigeria, pp.11.

World Health Organization (2001) Recommended classification of pesticides by hazard and guideline to classification 1998-1999,1999-2000and 2000-2001. WHO, Geneva, Switzerland. 